\title{
Defossilisation assessment of biodiesel life cycle production using the ExROI indicator
}

\author{
E. Font de Mora, C. Torres, A. Valero and D. Zambrana \\ Centre of Research for Energy Resources and Consumption - CIRCE \\ Universidad de Zaragoza, Mariano Esquillor, 15, 50018, Zaragoza (Spain) \\ 585496@celes.unizar.es
}

\begin{abstract}
Ensuring the sustainability of biofuels is a mandatory requisite for the EU Member States. The EU Renewables Directive focuses on the reduction of greenhouse gas emissions and the protection of high biodiversity and carbon stock lands. The current framework does not consider the consumption of non-renewable resources. Starting from the paper "Assessment of biodiesel energy sustainability using the ExROI concept" published in Energy [4], which defined the ExROI (Exergy Return on Investment) indicator and applied it to well-to-tank biodiesel production from rapeseed, sunflower and palm, this paper proposes extending the use of ExROI, which involves exergy cost accounting, to the life cycle; extending the calculations to soybean and used cooking oil; and assessing ways to "defossilise" the cycles. This paper demonstrates that the ExROI is a better indicator than the EROI (Energy Return on Investment) which only considers energy flows. Also, it shows that biodiesel life cycles have positive ExROI values and that the ExROI value can be improved up to 26.51 ; i.e. for one unit of non-renewable sources invested in the process more than 26 units of biodiesel are obtained. This means that biodiesel can be around five times more sustainable than fossil diesel, from the viewpoint of non-renewable resources consumption.
\end{abstract}

Keywords: Biodiesel; defossilisation; exergy cost; ExROI.

\section{Introduction}

A portfolio of alternative fuels, covering electricity, hydrogen, biofuels, methane, LPG and others, is necessary to meet the policy objectives of the European Union [1]. The National Renewable Energy Action Plans produced by the EU Member States setting the pathways to achieve the 2020 targets of the Renewable Energy Directive 2009/28/EC (RES Directive) [2], which aims at achieving a $10 \%$ use of renewable energies in transport, show that the $85 \%$ of the target for renewable energy in transport will come from first generation biofuels, i.e. conventional bioethanol and biodiesel. From these, biodiesel will play a substantial role, being $65.9 \%$ of the total target [3].

These biofuels will need to comply with the sustainability criteria set in the RES Directive which relate to the reduction of life cycle GHG emissions compared to fossil fuels, the protection of biodiversity and the exclusion of use of high carbon stock lands. Beyond these criteria, in order to ensure sustainability, it is necessary to defossilise the production life cycle as maximum, which means substituting non-renewable fuel energy sources and derived products used in the process, by renewable energy resources and derived products.

Based on the ExROI concept, defined in a previous paper [4], this paper proposes several alternatives to defossilise the biodiesel fuel life cycle. ExROI, Exergy Return on Investment is used to calculate the ratio of nonrenewable exergy consumed in the system to the exergy that the biodiesel contains. The less non-renewable exergy consumed, the higher the ExROI value will be. This definition is inversely equivalent to the non-renewable unit exergy cost $\left(\mathrm{c}_{\mathrm{p}}{ }^{\mathrm{nrs}}\right)$ which accounts the amount of nonrenewable resources required to obtain a product. The nonrenewable unit exergy cost is equivalent to the ratio of the exergy $(\mathrm{P})$ of the product and the non-renewable exergy cost of its production $\left(C_{p}{ }^{\mathrm{nrs}}\right)$.

$$
E x R O I=\frac{P}{C_{\mathrm{P}}^{n r s}}=\frac{1}{c_{\mathrm{P}}^{n r s}}
$$

The ExROI concept as used in this paper conjugates two important factors, life cycle assessment and exergy cost analysis. Life cycle assessment allows taking into account all non-renewable resources required from crop cultivation to the transesterification plant (primary processes), including the production of the required inputs (secondary processes), meanwhile exergy cost analysis permits the correct cost assessment taking into account the energy quality of the production flows. Exergy allows the integration of matter and energy flows in the analysis of production systems using the same concept and units for both.

An adequate selection of the boundaries of the system is very important, as in any life cycle analysis, thus depending on the processes included in the analyses the values obtained can vary significantly. Our previous paper [4] only took into account the direct production processes, while in this paper the production processes of the inputs to the direct production stages are also taken into account; this 
means for example the production of fertilisers used in the cultivation of the energy crops or the production on methanol for the transesterification process. This is a more accurate way of taking into account the exergy costs, as in the previous work, the exergy costs of the inputs entering the direct production processes were assumed to be their exergy values, following the theory of exergy cost [5]. By comparing the results of the previous publication with the results obtained in this one, we will be able to understand the weight that the secondary processes have in the consumption of non-renewable resources. The manufacture of machinery and equipment is not considered as this is neither considered in the sustainability criteria of the RES Directive.

This paper analyses the production life cycles of biodiesel from rapeseed, sunflower, palm, soybean and used cooking oil (UCO). Data used for carrying the calculations are mainly based on the life cycle assessment study (LCA) carried out by the JRC-EUCAR-CONCAWE consortium [6] (JEC study) which have been used by the European Commission to establish the sustainability criteria of the RES Directive and the Fuel Quality Directive (2009/30/CE) regarding the $\mathrm{CO}_{2}$ emissions from the cultivation of the raw materials to the production of biofuel. In the cases where information was missing from the published databases, other sources of information have been used. For example, the life cycle of the used cooking oil has been obtained from CIEMAT [7]. In the specific case of rapeseed biodiesel, a separate analysis has been produced using the SimaPro programme and EcoInvent database. This exercise will allow comparing the ExROI value obtained for one specific product using two different databases.

\section{Short description of the life cycles}

The biodiesel production processes vary depending on the resource. The biodiesel fuels based on energy crops, i.e. rapeseed, sunflower, palm and soybean begin by the cultivation process in order to obtain oil seeds, or fresh fruit bunches (FFB) in the case of palm plantations. In this stage, fertilizers, pesticides and energy is consumed in different quantities for each crop. From this, each resource follows different stages that are summarised in the Table 1. The processes for rapeseed, sunflower and palm oil were explained more in detail in paper [4]. The case of soybean based biodiesel is similar to the rapeseed and sunflower, but here there is no need for drying, and the transport needs increase since soybean is currently cultivated in South America and transported to Europe, where the refining and transesterification take place. The extraction is done by using n-hexane for all crops except for the palm oil. In addition, in the palm oil extraction the energy is obtained by burning palm biomass residues; methane and heat are obtained which in this work are considered as valuable coproducts.

The case of UCO is completely different. UCO is considered a residue which in case of not being used, would need to be disposed in a landfill. Given this, the previous stages before the oil becomes a residue (including the use, for example, in a frying pan) are not considered in the analysis. The life cycle starts by the collection and transport of the residue, and is followed by the recycling where the oil is filtered and decanted in order to separate solid particles and water. Once the oil is refined, it is sent to the transesterification plant.
Table 1. Direct processes considered in the life cycle analysis.

\begin{tabular}{|c|c|c|c|c|}
\hline $\begin{array}{l}\text { No. } \\
\text { proc }\end{array}$ & $\begin{array}{l}\text { Rapeseed, } \\
\text { sunflower }\end{array}$ & Palm & Soybean & UCO \\
\hline 1 & Cultivation & Cultivation & Cultivation & $\begin{array}{c}\text { Collection, } \\
\text { transport }\end{array}$ \\
\hline 2 & Drying & Road transport, Storage & $\begin{array}{l}\text { Road, } \\
\text { maritime } \\
\text { Transport }\end{array}$ & Recycling \\
\hline 3 & Transport & Extraction & Extraction & Transester. \\
\hline 4 & Extraction & $\begin{array}{l}\text { Road transport, Depot, } \\
\text { Maritime transport }\end{array}$ & $\begin{array}{l}\text { Maritime } \\
\text { transport }\end{array}$ & \\
\hline 5 & Refining & Refining & Refining & \\
\hline 6 & $\begin{array}{l}\text { Pretreat., } \\
\text { transester }\end{array}$ & Pretreat., transester. & $\begin{array}{l}\text { Pretreat., } \\
\text { transester. }\end{array}$ & \\
\hline 7 & $\begin{array}{l}\text { FAME } \\
\text { washing }\end{array}$ & FAME washing & $\begin{array}{c}\text { FAME } \\
\text { washing }\end{array}$ & \\
\hline 8 & $\begin{array}{l}\text { Glycerol } \\
\text { refining }\end{array}$ & Glycerol refining & $\begin{array}{l}\text { Glycerol } \\
\text { refining }\end{array}$ & \\
\hline
\end{tabular}

In the transesterification process the after-treatment of biodiesel (FAME washing) and the glycerol refining are treated separately to analyse the influence of glycerol in the ExROI calculation. This is the case for all the resources except for UCO where the glycerol is not refined.

\section{ExROI values}

The thermoeconomic model of the biodiesel production processes is represented by the productive diagrams for each of the direct processes considered in the life cycle analysis depicting the exergy flows entering and exiting each of the processes. As example, Figure 1 shows the case of rapeseed biodiesel production. Although this diagram only shows the direct processes, the exergy consumed for the production of the inputs is being accounted. From these diagrams it is possible to obtain the Fuel-Product table. Table 2 represents the Fuel-Product table for rapeseed, where $\mathrm{F}_{\mathrm{i}}$ refers to the process $i$ of the productive diagram of Figure 1.

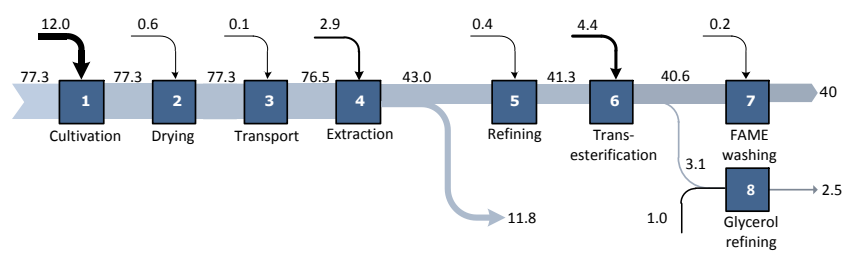

Figure 1. Productive diagram of rapeseed biodiesel life cycle production business as usual.

Table 2. Fuel-product table for rapeseed biodiesel life cycle production (MJ/kg FAME).

\begin{tabular}{|c|c|c|c|c|c|c|c|c|c|c|}
\hline & $F 1$ & $F 2$ & $F 3$ & $F 4$ & $F 5$ & F6 & $F 7$ & $F 8$ & $F O$ & Total \\
\hline $\mathrm{E}_{0}^{r s}$ & 77.3 & & & & & & & & & 77.3 \\
\hline $\mathrm{E}_{0}^{n r s}$ & 12.0 & 0.6 & 0.1 & 2.9 & 0.4 & 4.4 & 0.2 & 1.0 & & 20.7 \\
\hline$P 1$ & & 77.3 & & & & & & & & 77.3 \\
\hline$P 2$ & & & 77.3 & & & & & & & 77.3 \\
\hline$P 3$ & & & & 76.5 & & & & & & 76.5 \\
\hline$P 4$ & & & & & 43.0 & & & & 11.8 & 54.8 \\
\hline P5 & & & & & & 41.3 & & & & 41.3 \\
\hline P6 & & & & & & & 40.6 & 3.1 & & 43.7 \\
\hline$P 7$ & & & & & & & & & 40.0 & 40.0 \\
\hline$P 8$ & & & & & & & & & 2.5 & 2.5 \\
\hline Sum & 89.3 & 77.9 & 77.4 & 79.4 & 43.5 & 45.7 & 40.8 & 4.1 & 54.4 & \\
\hline
\end{tabular}


It is worth noticing that, as explained in [4], it has been assumed that the consumption of replenishable natural resources such as rain water, $\mathrm{CO}_{2}$ and solar energy in cultivation do not add exergy to the exergy costs. By doing this, the only irreversibilities taken into account for calculating the exergy costs are the ones provided by the non-renewable materials.

From the Fuel-Product tables it is possible to obtain the production costs of each process applying the theory of exergy cost [5]. Concisely, we apply its fundamentals as follows: in a specific stage of the process the exergy cost is distributed to all the products (main product and byproducts) of the stage proportionally by their exergy value; there is no exergy cost allocated to the waste produced; and the exergy cost of resources entering into the system is equal to their exergy.

Table 3 shows the non-renewable exergy costs $\left(\mathrm{C}_{\mathrm{p}}{ }^{\mathrm{nrs}}\right)$ and non-renewable unit exergy costs $\left(\mathrm{c}_{\mathrm{p}}{ }^{\text {nrs }}\right)$ of each process for the rapeseed biodiesel life cycle. It is worth noticing that the $c_{p}{ }^{\text {nrs }}$ of the refined glycerol is higher than the one of the final biodiesel. This means that the ExROI of glycerol would be 1.12 . The reason behind this high value is that the exergy of glycerol is low while the non-renewable exergy consumption is considerably high in the purification phase where a lot of energy is consumed in the distillation unit.

Table 3. Non-renewable costs $\left(C_{p}^{n r s}\right.$ in MJ/kg FAME) and unit exergy costs $\left(c_{p}{ }^{\text {nrs }}\right)$ of rapeseed based biodiesel production.

\begin{tabular}{llll}
\hline \multicolumn{1}{c}{ Process } & \multicolumn{1}{c}{$\begin{array}{c}\text { Business as } \\
\text { usual }\end{array}$} \\
\hline Cultivation & Seeds & $c_{p}{ }^{n r s}$ & $C_{p}{ }^{n r s}$ \\
Drying & Dried seeds & 0.156 & 12.05 \\
Transport & Dried seeds & 0.163 & 12.57 \\
Extraction & Crude vegetable oil & 0.166 & 12.71 \\
Refining & Refined oil & 0.282 & 15.49 \\
Transesterification & Crude biodiesel + crude & 0.305 & 12.59 \\
& glycerol & 0.387 & 16.93 \\
Biodiesel drying & Final biodiesel & 0.398 & 15.96 \\
Gly. purification & Refined glycerol & 0.890 & 2.22 \\
\hline
\end{tabular}

As explained above, the inverse of the unit exergy cost of the non-renewable resources of biodiesel gives the ExROI value according to Eq. (1). Table 4 shows the ExROI values, unit exergy costs $\left(c_{p}\right)$ and non-renewable unit exergy costs of the different biodiesel fuels $\left(c_{p}{ }^{n r s}\right)$. The non-renewable exergy cost and ExROI values are also calculated when using the exergy content of the inputs to the system instead of their exergy costs. The term "Difference" (ExROI with energy - ExROI with exergy costs) establishes the influence of the production processes of the inputs on the ExROI value. The term Renewability establishes the weight of the renewable exergy costs with respect the total exergy costs.

As it can be observed in Table 4, all the biodiesel sources have ExROI values higher than one, which means that for one unit of non-renewable resources used in their production, more than one unit of biodiesel is obtained. The most sustainable one is the biodiesel produced from used cooking oil, followed by palm, sunflower and rapeseed. The less sustainable is the soybean oil one which almost has a $1: 1$ relation.

The consideration of the production inputs (secondary processes) that enter the direct production processes plays an important role in the ExROI value as, except for the soybean oil based biodiesel, the ExROI is reduced in almost 2 units when the exergy costs, instead of the exergy values, are taken into account (see term Difference).

Table 4. EROI, ExROI, unit exergy cost, non-renewable exergy cost, Renewability and Difference for the different types of biodiesel fuels.

\begin{tabular}{l|ccc|cc|ccc}
\hline & \multicolumn{3}{|c|}{ Using Exergy Costs } & \multicolumn{2}{|c|}{ Using exergy values } & Dif. & EROI & Renew. \\
& $c_{p}$ & $c_{p}{ }^{n r s}$ & ExROI & $c_{p}{ }^{n r s}$ & ExROI & & & \\
\hline Rape & 1.81 & 0.40 & 2.51 & 0.23 & 4.37 & 1.86 & 2.68 & 78 \\
Sunfl. & 1.67 & 0.32 & 3.17 & 0.21 & 4.78 & 1.61 & 3.10 & 81 \\
Palm & 1.89 & 0.28 & 3.57 & 0.19 & 5.31 & 1.75 & 3.13 & 85 \\
Soy & 1.98 & 0.59 & 1.69 & 0.44 & 2.26 & 0.57 & 1.62 & 70 \\
UCO & 1.42 & 0.22 & 4.54 & 0.16 & 6.44 & 1.91 & - & 84 \\
\hline
\end{tabular}

Table 4 also shows the EROI values of the biodiesel fuels from energy crops. As it can be observed, this indicator shows very similar values for rapeseed, sunflower and palm oil biodiesels, while these fuels have quite different ExROI values. The reason behind this is that EROI value only takes into account the consumption of energy sources while the ExROI values also considers the consumption of mass flows. The rapeseed based biodiesel consumes more mass inputs than palm and sunflower giving as a result a lower ExROI value. These results demonstrate that the ExROI concept is a better indicator of resource sustainability than the EROI concept. The value for soybean is lower and similar to the ExROI value.

The ExROI values obtained above could be considered positive news and an objective indication of which biodiesel resources should be primarily promoted. Hall et al. [8] recommend that the minimum EROI society must attain from its energy exploitation to support continued economic activity and social function is about 3:1 and therefore, biodiesel which life cycle provides an ExROI value lower than 3 should introduce measures to improve their values or be discouraged.

In addition, the ExROI values of biodiesel fuels should be compared to its direct competitor, i.e. fossil diesel fuel. According to Cleveland [9], the EROI value of gasoline (and therefore of diesel as they are products of the same process) is in the range of 6 to 10 . Given this, the life cycle production processes should be defossilised in order to obtain at least the same ExROI values as fossil diesel fuel.

\section{Sensitivity analysis}

As it has been explained above, the results obtained are based on the consumption data of the life cycle assessments produced by the JRC, EUCAR and CONCAWE [6]. These numbers are fixed and based on specific assumptions. However, consumption in biodiesel production can vary significantly depending on many circumstances, for example, temperature and soil conditions at cultivation, carrying distance, quality of the oil at the transesterification plant, etc. This variation influences the exergy costs of the external resources entering the system and therefore the ExROI value of the product. In order to understand the effect that variations in the consumption of external resources may have in the ExROI result, a sensibility analysis is performed.

The exergy cost of the product can be calculated by the following equation: 


$$
\mathbf{C}_{P}={ }^{\mathrm{t}}\left\langle\mathbf{P}^{*}\right| \mathbf{C}_{e}
$$

Where $\mathrm{P}^{*}$ is the product matrix and $\mathrm{C}_{\mathrm{e}}$ is the exergy cost of the external resources entering into the system. As the external costs do not depend on the product matrix a variation in the exergy costs can be calculated by:

$$
\Delta \mathbf{C}_{P}={ }^{\mathrm{t}}\left\langle\mathbf{P}^{*}\right| \Delta \mathbf{C}_{e}
$$

If $\pi_{i j}^{*}$ is a generic element in the production matrix we obtain:

$$
\Delta C_{P, i}=\pi_{j i}^{*} \Delta C_{e, j}
$$

If we express Eq. (4) in terms of elasticity coefficient, and we only consider the non-renewable exergy costs, we obtain:

$$
\varepsilon=\frac{\% \Delta C_{P, i}^{n r s}}{\% \Delta C_{e, j}^{n r s}}=\frac{C_{e, j}^{n r s} \pi_{j i}^{*}}{C_{P, i}^{n r s}}
$$

Applying this equation to rapeseed biodiesel it can be obtained that a $10 \%$ variation of the non-renewable exergy costs entering the first process (cultivation) results in a variation of $5.5 \%$ in the production costs of the biodiesel product.

On the other hand, if we calculate the impact with respect the consumption of non-renewable resources following the elasticity coefficient of Eq. (6), we would obtain that an improvement on the efficiency of the system of $10 \%$ would result in an improvement of the ExROI value of $7.42 \%$.

$$
\frac{\% \Delta F_{T}^{n r s}}{\% \Delta k_{i}}=\frac{C_{F, i}^{n r s}}{F_{T}^{n r s}}
$$

This value shows that in face of possible variations, errors or deviations in the introduction of non-renewable resources consumption data into the system, the exergy cost does not vary significantly and, as a result, it indicates that the ExROI value is a consistent indicator.

\section{Defossilisation of rapeseed life cycle}

This section analyses the impact of different actions that could be introduced in the life cycle of rapeseed based biodiesel in order to defossilise the process and obtain higher ExROI values. Given the allocation system applied as defined by the theory of exergy cost, such actions should focus on reducing the consumption of non-renewable resources; decreasing the production of residues; finding a value for the residues, in order to allocate exergy costs to their flows; and reducing the amount of inputs, which reduces the exergy entering the system and therefore the exergy costs of the products. The results of the actions explained in this paragraph are gathered in Table 6.

Starting from the cultivation unit, the first possible action is the use of organic fertilizers instead of inorganic fertilizers which consume high quantities of non-renewable resources. The organic fertilizer considered is compost which provides NPK, for which mass and energy consumption data have been obtained from the EcoInvent database [10]. In such a case, the ExROI value is improved in $58 \%$, i.e. to 3.97 , assuming that with the use of this fertiliser the same yield is obtained.

Another possibility in this stage is the selection of crop varieties with high oil contents. The JEC study considers that rape seeds have a content of oil of $0.405 \mathrm{~kg}$ of oil $/ \mathrm{kg}$ of seed. If we choose a seed with an oil content of $0.445 \mathrm{~kg}$ of oil $/ \mathrm{kg}$ of seed [11], which is a $9.9 \%$ higher, an ExROI of 2.56 is obtained, which is a $2 \%$ higher than the business as usual case.

Finally, if $50 \%$ of the straw produced at the site is collected and considered as a co-product of cultivation instead of a residue, the ExROI is increased up to 3.42 which is a $36 \%$ higher than the business as usual scenario. This scenario assumes that by taking half of the straw which otherwise would stay on the ground, no additional use of fertilisers to cover the potential soil quality losses are needed. This is an interesting solution to reduce the allocation of non-renewable exergy costs consumed in this stage to the main product without affecting the fertility of the soil [12].

In the oil extraction process, the most interesting action is the production of biogas from the rapeseed meal obtained. If this biogas is used in the cycle in order to reduce the use of fossil fuels the ExROI value is increased in $18 \%$, i.e. up to 2.95 .

In the transesterification unit there are many actions that can be considered. On the one hand, these relate to the substitution of fossil fuel derived methanol by other resources from renewable origin. This would be the case when methanol produced from wood or bioethanol from wheat, are used. In the first case the ExROI value would be increased by $23 \%$ (3.08) and in the second case by $14 \%$ (2.86). On the other hand, they relate to the partial reintroduction of FAME into the cycle in order to substitute the use of fossil fuels. This substitution could be direct or indirect. Direct substitution consists in the use of biodiesel instead of diesel or heavy oil in the cultivation, drying and transport processes; an indirect use consists in the use of biodiesel instead of fossil energy in the production of the inputs that enter the direct process of the biodiesel production cycle. In both cases, the ExROI is improved by $10 \%$ (2.76) and $3 \%$ (2.58), respectively, for the considered quantity of biodiesel retrofitted.

On the contrary to what could be considered, the anaerobic digestion of the glycerol of the production cycle in order to produce biogas which would be consequently used in the cycle to substitute fossil sources does not increase the ExROI value, but reduces it in -3\% (2.44). This could be caused by the low biogas yield of glycerol.

If instead of producing biodiesel, we consider the refined vegetable oil as a biofuel to be used directly in adapted engines, the ExROI value of this product for which no transesterification would be needed, would be 3.28 which is a $31 \%$ higher than for biodiesel. This provides an indication of the weight that transesterification has in the biodiesel life cycle production.

All these actions applied separately do not provide an ExROI value higher than the EROI of fossil diesel fuel, according to Cleveland [9]. However, if we consider the following actions together, we can obtain an ExROI of 26.51 which is $956 \%$ higher than the reference situation and quite higher than fossil diesel fuel: 
- Use of organic fertilizer instead of inorganic fertilizers;

- Conversion of rapeseed meal to biogas and use in the process;

- Use of seed varieties with high oil content;

- Use of methanol from wood in the transesterification process;

- Partial consumption of biodiesel in the cycle.

Figure 2 shows the productive diagram of this case scenario with all the recirculations of exergy considered. Table 5 shows the non-renewable exergy costs for this scheme where the improvements have been implemented.

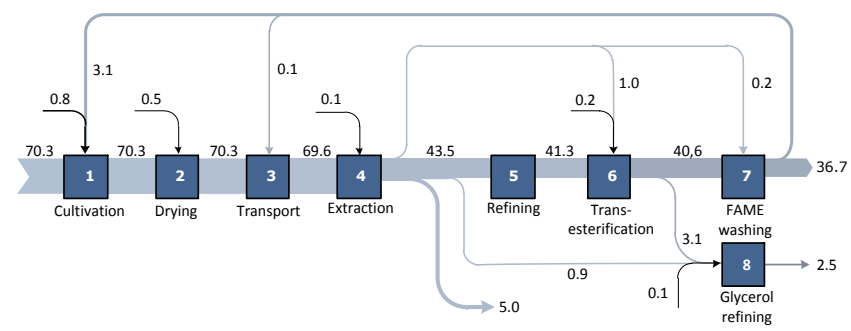

Figure 2. Productive Diagram of rapeseed biodiesel life cycle production combining several defossilisation actions.

Table 5. Non-renewable costs $\left(C_{p}{ }^{n r s}\right.$ in $\left.M J / k g ~ F A M E\right)$ and unit exergy costs $\left(c_{p}{ }^{\text {nrs }}\right)$ of rapeseed based biodiesel applying improvement measures.

\begin{tabular}{llcc}
\hline & & \multicolumn{2}{c}{ Improved process } \\
\hline Process & Product & $c_{p}{ }^{\text {rrs }}$ & $C_{p}{ }^{\text {rrs }}$ \\
\hline Cultivation & Seeds & 0.013 & 0.92 \\
Drying & Dried seeds & 0.020 & 1.38 \\
Transport & Dried seeds & 0.020 & 1.39 \\
Extraction & Crude vegetable oil & 0.030 & 1.53 \\
Refining & Refined oil & 0.032 & 1.33 \\
Transesterification & Crude biodiesel + & 0.036 & 1.59 \\
& crude glycerol & 0.038 & 1.51 \\
Biodiesel drying & Final biodiesel & 0.090 & 0.22 \\
Gly. purification & Refined glycerol & & \\
\hline
\end{tabular}

Table 6. ExROI values applying improvement measures and percentage of variation compared to the business as usual scenario.

\begin{tabular}{lcc}
\hline Defossilisation options & & $\%$ \\
\hline Business as usual & 2.51 & 0 \\
Use of organic fertilizers of biologic origin & 3.97 & 58 \\
Using plants with high oil content & 2.56 & 2 \\
Use 50\% of straw as a useful co-product & 3.42 & 36 \\
Anaerobic digestion of meal to biogas & 2.95 & 18 \\
Using methanol from wood instead of fossil & & \\
methanol & 3.08 & 23 \\
Using bioethanol from wheat instead of fossil & & \\
methanol & 2.86 & 14 \\
Partial consumption of FAME in the cycle (direct & & \\
use) & 2.76 & 10 \\
Partial use of FAME in the production of resources & & \\
(indirect use) & 2.61 & 4 \\
Anaerobic digestion of glycerol to biogas & 2.44 & -3 \\
PVO - Pure Vegetable oil & 3.28 & 31 \\
Combination of several improvement actions & 26.51 & 956 \\
Considering glycerol as residue & 2.33 & -7 \\
Sensibility analysis: meal higher energy value. & & \\
Source: I.D.A.E & 3.14 & 25 \\
SIMAPRO EcoInvent database & 2.99 & 19 \\
\hline
\end{tabular}

It is worth noticing that there could be situations that could worsen the ExROI of biodiesel production. For example, in the case that the glycerol produced in the transesterification process could not be sold as a product but instead treated as a residue, due to the saturation of the glycerol market. In this case, the ExROI would be reduced up to 2.33 i.e. a $7 \%$ lower than the case of glycerol being a valuable product.

To conclude the analysis, it is important to note that there are certain values and conversion factors that have not been homogenised and could vary substantially, having this variation a significant impact in the ExROI value. This could be the case for example of the exergy content of the rapeseed meal considered. In this paper, the exergy content of the meal has been considered to be $7.4 \mathrm{MJ} / \mathrm{kg}$, which is the metabolisable energy according to [13]. This is the useful energy animals can profit of when eating the meal. If instead this value we take $21.1 \mathrm{MJ} / \mathrm{kg}$ which is the value assumed by [14] for the allocation of $\mathrm{CO}_{2}$ emissions and energy consumption in the life cycle analysis, we obtain that for the same conditions, the ExROI value is increased in $25 \%$, i.e. up to 3.14 .

Finally, if EcoInvent database is used instead of the data used in the JEC study, the ExROI value obtained is equal to 2.99 , which is $19 \%$ higher. EcoInvent is currently the world leading life cycle inventory data source. Taking into account this database the processes and consumption data considered in the cycle are slightly different than the ones considered in the JEC study [6]. These two last results show the need of standardise the input and conversion factors in the methodology of ExROI calculation.

\section{Conclusions}

This paper is a continuation of paper [4] published in Energy. There the ExROI value was defined and applied to biodiesel production processes: rapeseed, sunflower and palm oil based biodiesels. Here, the number of biodiesel production processes is widened, including soybean and used cooking oil, and the boundaries of the system have been amplified to take into account not only the direct or primary processes: cultivation, transport, extraction, refining, transesterification; but also the secondary processes, i.e. the processes to produce the materials and energy used in the primary processes. With this, this paper relates the ExROI and exergy costs calculations with the life cycle analysis discipline.

The results show that biodiesel life cycles are sustainable from the point of view of the use of nonrenewable resources, although improvements are necessary as the ExROI value is considered to be low in the business as usual scenario. While these values range from 1.69 for soybean biodiesel to 4.54 for biodiesel from UCO, the EROI value of diesel fossil is estimated by Cleveland to be around 6. Given this, it is considered that ExROI values higher than 6 must be achieved. This paper demonstrates that by conjugating several defossilisation improvements, which deal with the substitution of fossil materials by renewable materials, the recirculation of biodiesel and reduction of inputs, ExROI values of around 27 can be obtained, which means more than quadrupling the EROI value of fossil diesel. These measures should also be studied from an economic, social and environmental point of view in order to certify their viability. This work is currently being performed and will be shown in future publications. 


\section{Nomenclature}

$c \quad$ unit exergy cots

$C \quad$ exergy cost (MJ/kg FAME)

$E \quad$ exergy (MJ/kg FAME)

$\varepsilon \quad$ elasticity coefficient

EROI energy return on energy investment

ExROI exergy return on exergy investment

$F \quad$ Exergy of the fuel

$F A M E$ fatty acid methyl ester (biodiesel)

$F F B \quad$ fresh fruit bunches

$k \quad$ exergy consumption (MJ/kg FAME)

$P \quad$ exergy of the product (MJ/kg FAME)

$\langle\mathbf{P} *|$ production cost operator matrix

$\pi$

generic element of the production matrix

$\begin{array}{ll}\text { Subscripts and superscripts } \\ \text { e } & \text { external resources } \\ \text { eq } & \text { equivalent } \\ \text { nrs } & \text { non renewable sources } \\ \text { P } & \text { product } \\ \text { rs } & \text { renewable sources } \\ \text { t } & \text { transpose matrix } \\ * & \text { exergy cost } \\ 0 & \text { environment }\end{array}$

\section{References}

[1] CARS 21 High Level Group, "Competitiveness and Sustainable Growth of the Automotive Industry in the European Union," Brussels, June 6, 2012.

[2] L.W.M. Beurskens et al., "Renewable Energy Projections as Published in the National Renewable Energy Action Plans of the European Member States, Covering all 27 EU Member States with updates for 20 Member States," ECN (Energy Research Centre of the Neatherlands), EEA (European Environment Agency). ECN-E-10-069, 2011.

[3] Directive 2009/28/EC of the European Parliament and of the Council of 23 April 2009 on the promotion of the use of energy from renewable sources and amending and subsequently repealing Directives 2001/77/EC and 2003/30/EC, Official Journal of the European Union, June 6, 2009.
[4] E. Font de Mora, C. Torres, A. Valero, "Assessment of Biodiesel Energy Sustainability Using the Exergy Return on Investment Concept," Energy, 45 (1), pp. 474-480, 2012.

[5] M.A. Lozano, A. Valero, "Theory of the exergetic cost," Energy, 18, 939-960, 1993.

[6] JEC - Joint Research Centre-EUCAR-CONCAWE collaboration. (2011). Well-to-Wheels Analysis of Future Automotive Fuels and Powertrains in the European Context (version 3c) [Online]. Available: http://iet.jrc.ec.europa.eu/

[7] Y. Lechón et al., "Análisis de ciclo de vida de combustibles alternativos para el transporte. Fase I. Análisis de ciclo de vida comparativo del biodiesel de cereales y de la gasolina," Ministerio de Educación y Ciencia y Ministerio de Medio Ambiente, Madrid, Spain, 2005.

[8] C.A.S. Hall et al., "What is the minimum EROI that a sustainable society must have?," Energies, 2, 25-47, 2009.

[9] C.J. Cleveland, "Net energy from the extraction of oil and gas in the United States," Energy, 30,769-782, 2005.

[10] EcoInvent. EcoInvent database [Online]. Available: http://www.ecoinvent.org/

[11] BIO Intelligence Service, "Life Cycle Assessment applied to first generation biofuels consumed in France," ADEME, France, 2010.

[12] K. Christa, W. Elisabeth, "Biomass report," MixBioPells project, Intelligent Energy - Europe programme, supported by the European Commission.

[13] Iowa Soybean Association. Comparative Composition of Various Oilseed Meals [Online]. Available: http://www.soymeal.org.

[14] Y. Lechón et al., "Evaluación del balance de gases de efecto invernadero en la producción de biocarburantes. Estudio Técnico PER 2011-2020," IDAE, Ministerio de Industria, Energía y Turismo, Madrid, Spain, 2011. 